G361(P) SEVERE SEPSIS AMONG PAEDIATRIC PATIENTS WITH SICKLE CELL DISEASE: A REGIONAL CASE SERIES

${ }^{1,2} \mathrm{E}$ Wall, ${ }^{3} \mathrm{~J}$ Brent, ${ }^{2} \mathrm{M}$ Velangi. ${ }^{1}$ Postgraduate School of Paediatrics, West Midlands Deanery, Birmingham, UK; ${ }^{2}$ Haematology and Oncology Department, Birmingham Women's and Children's NHS Foundation Trust, Birmingham, UK; ${ }^{3}$ Children's and Adolescent Services, The Royal Wolverhampton NHS Trust, Wolverhampton, UK

10.1136/archdischild-2018-rcpch.351

Aims We aimed to conduct a case series review of severe sepsis episodes in patients with sickle cell disease at a large regional paediatric centre in the UK. We aimed to examine sickle cell disease prior to episode, compliance with sepsis prevention, type of infection including the organism isolated, sequelae, and outcome.

Methods Retrospective cumulative case series of severe sepsis admissions over the last 5 years among our cohort of patients with sickle cell disease at a large paediatric regional centre in the UK. Data was extracted from the department's sickle cell database and from clinical records.

Results We present 5 cases of severe sepsis among our regional cohort of 388 children with sickle cell disease. The patients presented within a 2 year period between May 2015 and May 2017. The ages of the patients ranged from 2 to 11 (median age 3 years). It was the first admission to hospital in $3 / 5$ cases. One patient was on hydroxycarbamide, and all 5 had a normal TCD. Four out of 5 were compliant with penicillin and had received childhood vaccines, and $3 / 5$ had received the polysaccharide pneumococcal vaccine. The organisms isolated were Strep. pneumoniae (3 cases), E. coli (1 case), and Salmonella durham (1 case). Sepsis was often rapidly progressive and presented atypically. Two of the 5 patients died following sepsis episode. Both had pneumococcal sepsis. There was significant morbidity in survivors. Complications included osteomyelitis (2 cases), pathological fracture (1 case), hearing impairment and central diabetes insipidus secondary to meningoencephalitis (1 case) and necrosis of the fingertips. In the pneumococcal cases, either patient was not covered with vaccination, or the organism had partial resistance to penicillin.

Conclusion Despite advances in recent years following introduction of sepsis prevention measures, sepsis remains an important cause of mortality and morbidity in paediatric patients with sickle cell disease. Sepsis often presents rapidly and atypically in this group of patients.

\section{G362(P) HAS NICE GUIDELINE FOR SUSPECTED PAEDIATRIC CANCER MADE A DIFFERENCE IN DIAGNOSIS?}

M Aye. Paediatric, Milton Keynes University Hospital NHS Trust, Milton Keynes, UK

\subsection{6/archdischild-2018-rcpch.352}

Children and young people with possible cancer usually present to their primary care physician first. NICE has published and updated guideline for suspected paediatric cancer referral. The aim of this study is to find out improvement in diagnosis of cancer among those group of patient via 2 weeks wait (WW) referral.

Method This is retrospective review of 2 WW referral forms and outcome from Electronic medical notes. Our POSCU (Paediatric oncology share care unit) 2 WW cancer referral audit was carried out between November 2014 to January 2017.

Results Total of 56 referrals was received during the 27 months. Only 2 children (3.6\%) had cancer. Most of the referrals (98\%) were seen within 2 weeks. The most common reason for referral is lymphadenopathy (39\%) which is similar to other studies. Other reasons for referral include: fatigue, malaise and weight loss, headache/CNS signs, bony, abdominal and soft tissue mass, bruising, and non-specific symptoms.

Conclusion This study confirmed that updated 2015 NICE guideline for cancer referral has not improved in pick-up rate of cancer.

The finding from this study is similar to other studies;

- Abomeli et al. (Dec12 to 14) 83 referrals, had cancer

- Mant et al. (2007-2010) 35 referrals, 1 had cancer

- Ling et al. (2009-1012) 118 referrals, 2 had cancer

- Galloway et al. (2012 to 2015) 81 referrals, 2 had cancer.

- Roskin et al. (2004-2014) 93 referrals, 2 had cancer

From the above 5 studies, 6 children (1.9\%) were diagnosed with cancer in 317 referrals during 2004 to 2015. In our study, it was $3.6 \%(2 / 56)$. The pick-up rate of cancer hasn't changed much.

According to the NICE guideline, some of the presentations should be referred very urgently (within 48 hours) for specialist assessment. However, all of the referrals from our study were received for 2 weeks. Regular teaching sessions and development of referral pathway for the local GPs should help in improving the knowledge on early referral and diagnosis. GPs should be able to contact urgently if concerned instead of using referral pathway as a way of jumping the queue.

\section{G363(P) THE UTILITY OF WHOLE- BLOOD AND LINEAGE- SPECIFIC CHIMERISM IN PREDICTING GRAFT FAILURE AFTER STEM CELL TRANSPLANTATION FOR NON- MALIGNANT DISEASE}

${ }^{1} \mathrm{M}$ Neocleous, ${ }^{2} \mathrm{R}$ Wynn, ${ }^{2} \mathrm{~S}$ Lum, ${ }^{3} \mathrm{H}$ Lee, ${ }^{4} \mathrm{H}$ Church. ${ }^{1} \mathrm{~S} c h o o l$ of Medicine, University of Manchester, Manchester, UK; ${ }^{2}$ Bone Marrow Transplant Unit, Royal Manchester Children's Hospital, Manchester, UK; ${ }^{3}$ Transplantation Laboratory, Manchester Royal Infirmary, Manchester, UK; ${ }^{4}$ Genomic Diagnostics Laboratory, St Mary's Hospital, Manchester, UK

\subsection{6/archdischild-2018-rcpch.353}

Background and aims Allogeneic haematopoietic stem cell transplantation (HSCT) is widely used to treat non-malignant conditions. Mixed chimerism (MC) is an increasingly observed phenomenon in such cases. This study's purpose was to explore predictors of $\mathrm{MC}$ and graft failure, variations in outcome between patients with complete chimerism (CC) and $\mathrm{MC}$, and the utility of lineage-specific chimerism in predicting graft outcomes.

Methods Our patient sample included 284 HSCTs performed in children with non-malignant conditions between July 2000 and March 2017 at our centre. The following variables were considered in each patient: gender, age at transplant, date of transplant, disease, conditioning regimen, T-cell depletion, donor and stem cell source, alive/deceased status, chimerism status. Variables were assessed using univariate and multivariate logistic regression analysis. The relationship between myeloid 
chimerism, T-cell chimerism and transplant outcomes was also investigated in those patients with lineage-specific analysis.

Results In total, 186 patients exhibited CC while 98 patients exhibited MC. Mean age at transplant and conditioning were identified as significant predictors of MC. Year of transplant and chimerism status were identified as significant predictors of graft failure. In 29 out of 49 patients with high-level MC, graft failure was developed. Early myeloid complete donor chimerism was identified as a useful predictor of long- term engraftment and a rising donor T-cell chimerism. Subsequently, an algorithm was created for the clinical management of chimerism in non-malignant disease.

Conclusions High-level MC is a better predictor of graft failure than low-level MC. Myeloid chimerism can be used as a reliable indicator of the transplant outcome. T-cell chimerism monitoring can be important in patients with T-cell immunodeficiencies. The algorithm suggested is used to inform and predict graft outcomes as well as the need for specific interventions in patients with a non-malignant disease, whilst utilising lineage- specific (myeloid and T-cell) chimerism.

\section{G364(P) DELAYS TO DIAGNOSIS OF CHILDHOOD CANCER: A QUALITATIVE STUDY OF SPECIALIST HEALTH CARE PROFESSIONALS' VIEWS}

${ }^{1} \mathrm{H}$ Bowyer, ${ }^{2} \mathrm{M}$ Girling, ${ }^{3} \mathrm{C}$ Exley, ${ }^{1} \mathrm{D}$ Tweddle. ${ }^{1}$ Northern Institute of Cancer Research, Newcastle University, Newcastle Upon Tyne, UK; ${ }^{2}$ Institute of Health and Society, Newcastle University, Newcastle Upon Tyne, UK; ${ }^{3}$ Research and Innovation Department, Northumbria University, Newcastle Upon Tyne, UK

\subsection{6/archdischild-2018-rcpch.354}

Aims Specialist health care professionals (SHCPs) working in Paediatric Oncology Principle Treatment Centres (PCTs) can provide invaluable insights into diagnostic pathways and the consequences of delays in diagnosis of childhood cancer. This study is the first to explore their views on the significance of delays in diagnosis of childhood cancer and reports their suggestions of how delays could be reduced.

Methods Semi-structured interviews were conducted with 20 SHCPs working in a variety of paediatric oncology specialist roles within PCTs throughout the UK. SHCPs included clinicians, nurses and allied healthcare professionals. Interviews were audio-recorded, transcribed verbatim and analysed using thematic analysis.

Results SHCPs believe that delays in diagnosis childhood cancer can have important psychological and physical consequences. They believe there are many barriers to an efficient childhood cancer diagnosis within the UK, but especially within the primary-care setting. They recognise that the rarity of childhood cancer and the variability of presenting symptoms may make raising awareness a challenge. SHCPs instead would like to see changes to how community paediatric healthcare is delivered, suggesting the UK re-consider the introduction of primary-care paediatricians and routine surveillance of children.

Conclusion SHCPs believe that considerable changes to how paediatric healthcare is delivered in the UK could improve overall childhood health, but could also reduce delays in diagnosis of many conditions including cancer.

Acknowledgement This study was fully funded by Cancer Research UK and was supported by Children's Cancer and Leukaemia Group (CCLG).

\section{G365(P) RETROSPECTIVE COHORT STUDY OF (P)IOR REVERSIBLE ENCEPHALOPATHY SYNDROME (PRES) IN PAEDIATRIC ONCOLOGY PATIENTS OVER A 10 YEAR PERIOD}

'VMY Wong-Spracklen, 2B Messahel, 'D Krishnakumar. 'Paediatric Neurology, Addenbrooke's Hospital, Cambridge University Hospitals NHS Trust, Cambridge, UK; ${ }^{2}$ Paediatric Oncology and Haematology, Addenbrooke's Hospital, Cambridge, UK

\subsection{6/archdischild-2018-rcpch.355}

Aims Literature regarding (P)ior reversible encephalopathy syndrome (PRES) in paediatric oncology is limited. Clinical symptoms of PRES include seizures, headaches, altered consciousness, and visual disturbances. We describe the seizures in PRES, outcomes and need for anti-epileptic medication of this clinical syndrome.

Methods A retrospective cohort study using data from the East Anglia paediatric oncology database for suspected adverse events (SAE) from chemotherapy was conducted. Oncology patients aged 16 and below, from 1 January 2007 until 15 June 2017 who had developed seizures while undergoing chemotherapy, were included. We identified the chemotherapy administered before onset of seizures, magnetic resonance imaging (MRI) reports, and patient outcomes based on antiepileptic drugs (AED) requirement at 6, 12, 24 months or more after seizure occurrence.

Results 38/420 (9.0\%) paediatric patients undergoing chemotherapy developed seizures. $14 / 38$ (36.8\%) were confirmed to have had PRES. The mean age for PRES-associated seizures was 10.1 years ( \pm SD 3.7 years). The mean interval between administration of chemotherapy and onset of seizures in PRES was 7 days \pm SD 5 days (Median 5 days, range 1-17 days). Chemotherapy agents associated with seizure occurrence in PRES were methotrexate in $10 / 14$ (71.4\%), ifosfamide in $3 / 14$ (21.4\%) and vincristine 1/14 (7.1\%). High signal abnormalities seen on MRI changes due to PRES was seen in occipital-parietal lobe (43\%), frontal lobe (43\%), centrum semiovale (14\%), caudate nucleus (14\%), deep white matter (14\%) and temporal lobe $(7 \%)$. Only $1 / 14(7 \%)$ of PRES patients remained on AED for 11 months, compared to $3 / 24$ (12\%) of non-PRES patients who remained on AED at 5 years follow-up.

Conclusion PRES is an important differential to consider in paediatric oncology population developing seizures. The chemotherapeutic agents associated with PRES are often Methotrexate, Vincristine and Ifosfamide. The outcome for seizures associated with PRES is good as only $7 \%$ require anti-epileptic medication for the first 11 months post-PRES. Further studies should be carried out in identifying prognostic markers, e.g. blood pressure, which may aid early identification of patients at risk of PRES and who may benefit from proactive preventative measures.

\section{G366(P) SYSTEMATIC REVIEW ON THE USE OF HYDROXYCARBAMIDE IN REDUCING TRANSCRANIAL DOPPLER VELOCITIES IN CHILDREN WITH SICKLE CELL ANAEMIA AND WHETHER THIS RESULTS IN STROKE PREVENTION}

S Mason. Clinical School, University of Cambridge, Cambridge, UK

\subsection{6/archdischild-2018-rcpch.356}

Introduction Sickle cell anaemia is a common inherited haemoglobinopathy in which distorted red blood cells cause vasoocclusion and ischaemic-reperfusion injury in various organs. 